\title{
PALIMPSESTO: UMA POSSIBILIDADE DE EXPRESSÃO PARA OS DESIGNERS
}

\author{
Leonardo Coelho Siqueira - Graduando em Design Gráfico na Universidade \\ Federal de Pelotas \\ leonardosqra@gmail.com
}

\author{
Helena de Araujo Neves - Professora Adjunta nos cursos de Design na \\ Universidade Federal de Pelotas \\ profhelena.neves@gmail.com
}

Orientação: Prof. ${ }^{a}$ Dr. ${ }^{a}$ Helena de Araujo Neves

\section{RESUMO}

Este artigo foi produzido para a disciplina de História do Design e tem a intenção de debater o conceito do palimpsesto, além de fazer um mapeamento de seu uso nas mais variadas formas de expressão. O intuito é o de também, futuramente, criar peças que se utilizem da estética do palimpsesto. Os dados encontrados até esta fase do estudo indicam que mesmo que um designer busque dotar uma peça (criada com a estética do palimpsesto) de um sentido objetivo, essa objetivação da obra poderá não ocorrer. Isso porque ela será interpretada pelo espectador - ainda que o produtor procure conduzir essa interpretação - e talvez aí resida a profundidade de tal estética.

Palavras-chave: Palimpsesto, História do Design, História da Arte, Artes Gráficas.

\section{INTRODUÇÃO}

Este artigo deriva-se de uma pesquisa ${ }^{1}$, previamente realizada junto à disciplina de História do Design dos cursos de Design da UFPel, que teve como temática a estética do palimpsesto. O palimpsesto teve origem praticamente junto com a escrita, nasce do reaproveitamento de papiros; por meio dos registros rupestres, dentre outras formas de apreensão da escrita.

\footnotetext{
${ }^{1}$ Pesquisa realizada para a disciplina de História do Design na Universidade Federal de Pelotas. Foi elaborada pelos acadêmicos: Camila Porto Burguêz, Camila Schiavon dos Santos, Leonardo Coelho Siqueira e Vinicius Oteiro Corrêa. Neste momento, contudo, o estudo foi aprofundado por um dos acadêmicos e por sua professora e é apresentado neste artigo.
} 
Essa estética foi pouco analisada em termos de design e existem poucos estudiosos que desenvolvem suas pesquisas em torno do tema associado ao design. É por essa razão que se apresenta este artigo, que foi organizado com a intenção de mapear alguns estudos já apresentados sobre esse tema, tendo também por objetivo produzir, futuramente, algumas peças contemporâneas levando em consideração os pressupostos do palimpsesto.

\section{O PALIMPSESTO: POSSÍVEIS APROPRIAÇÕES PARA O CAMPO DO DESIGN}

Desde o modernismo o palimpsesto vem se destacando no campo das artes, mas teve seu desenvolvimento deflagrado no período denominado de pós-moderno.

O modernismo foi um importante marco para o design no mundo inteiro, nesse momento era apregoado que o design deveria propor formas mais limpas e funcionais. Tendo como lema "a forma segue a função" os projetos desenvolvidos nesse período perderam as curvas ganhando ângulos retos, além de geometrização na construção das peças. As obras modernistas são, grande parte, objetivas em todos os aspectos, tendo como maior contribuição para a difusão desse pensamento projetual a conhecida Escola Bauhaus, criada na Alemanha (CAUDURO, 2000).

Pós-modernismo no que se refere à estética, por sua vez, foi um período em que a técnica do palimpsesto foi muito utilizada, isso porque nesse momento,

\footnotetext{
tudo é possível, a criação torna-se sinônimo de improvisação, o signo procede seu referente, o ícone inventa seu objeto, e o índice gestual é o que vale, pois é o que garante a autoria (CAUDURO, 2000. p. 129).
}

Com a industrialização e a implementação do capitalismo fortificado, o consumo de massa ganhou espaço na sociedade. No campo do design isso não foi diferente, designers começaram a ter seus projetos voltados ao consumo, sendo contratados para realizar projetos que buscavam a produção em série. A reflexão da proliferação do consumo da massa foi provocada principalmente pelo movimento Pop Art - que se utilizou da repetição - como uma crítica para a efemeridade daquilo que era produzido na era industrial. Este movimento foi um marco entre a então "ruptura" que nascia na arte mundial: modernismo x pós-modernismo. As linhas caem, juntamente com os 
ângulos e grids extremamente rígidos. As tipografias ganham novos formatos, incluindo muitas curvas. $\mathrm{O}$ pós-modernismo então está instalado: isso faz a presença da arte como expressão que toca de várias maneiras, os diferentes olhares e culturas. Dentre outras características, o pós-modernismo abriu portas para o debate acerca do conceito da obra de arte, ligando este ao significado, isto é, a interpretação da obra toma o espaço da estética, buscando uma maior experiência e participação do espectador. Este aspecto do movimento pós-moderno é muito significativo para o palimpsesto, uma vez que o seu uso, normalmente, não prioriza a estética ou o sentido imediato, mas sim a experiência do espectador da obra assim como a(as) interpretação(ões) advinda(as) de diferentes olhares. Com a difusão do uso do palimpsesto na era pós-moderna Cauduro (2000, p. 129), afirma que "a produção do sentido da obra artística é responsabilidade delegada agora ao espectador".

Ainda com relação ao pós-modernismo Meggs (2009), caracteriza-o em quatro principais vertentes. A primeira pode ser exemplificada pela rebeldia da New Ware Typography integrada pelos novos designers suíços no início da década de 1970. A segunda vertente foi integrada pelos maneirismos e pelas exuberantes e exóticas práticas dos designers do Grupo Memphis de Milão. Em um terceiro momento o movimento Retrô se estabelece, propondo um novo repertório gráfico que se impõe como inovador, trazendo as soluções vernaculares e modernistas europeias no período entre guerras, apresentando um estilo excêntrico e diverso. E, por último, mas não menos importante, encontra-se a revolução digital - que foi originada, segundo a historiografia do Design, pelo aparecimento do computador gráfico pessoal Mcintosh. Para Cauduro (2000), foi a partir dessas vertentes que os projetos em design passaram a ser menos calculistas e mais intuitivos, muitas vezes irônicos, quase sempre provocantes e muito criativos. $\mathrm{O}$ estudioso destaca que essas características intensificaram a força do design em todo mundo, apresentando projetos mais bem elaborados, uma vez que "esse recurso não permite que se esgotem as possibilidades de geração de sentido, e assim mantém presa a atenção dos sujeitos interpretantes por muito tempo" (CAUDURO, 2000, p. 133).

Outro aspecto importante de ser destacado são os esforços em definir o termo palimpsesto. De acordo com o dicionário American Heritage (2015) palimpsesto é, respectivamente, 
um manuscrito, tipicamente de papiro ou pergaminho, que foi escrito em mais de uma vez, com a redação anterior incompleta raspado fora ou apagado e muitas vezes legível (AMERICAN HERITAGE DICTIONARY², 2015).

Segundo Martins (1996), os primeiros suportes utilizados pela escrita humana: a pedra (arte rupestre, 10 mandamentos, inscrições Maias, etc.), o mármore (inscrições tumulares e cívicas Grego-Romanas), a argila (gravações em tábuas nas bibliotecas da Mesopotâmia) assim como nos diversos metais - como bronze, chumbo, prata e o ouro - em ocasiões excepcionais. Estes suportes ainda hoje são utilizados com as mais diversas funções e, muito vezes, são reaproveitados como, por exemplo, nas chapas utilizadas para a editoração de jornais, ou mesmo nos fotolitos usados em gráficas (ver Fig.1). O alto valor dessas ligas metálicas justifica a reutilização e, por vezes, uma sobreposição de mensagens que ocorre pelo reuso do material- o que acaba por dar origem aos palimpsestos que podem se tornar verdadeiras obras de arte.

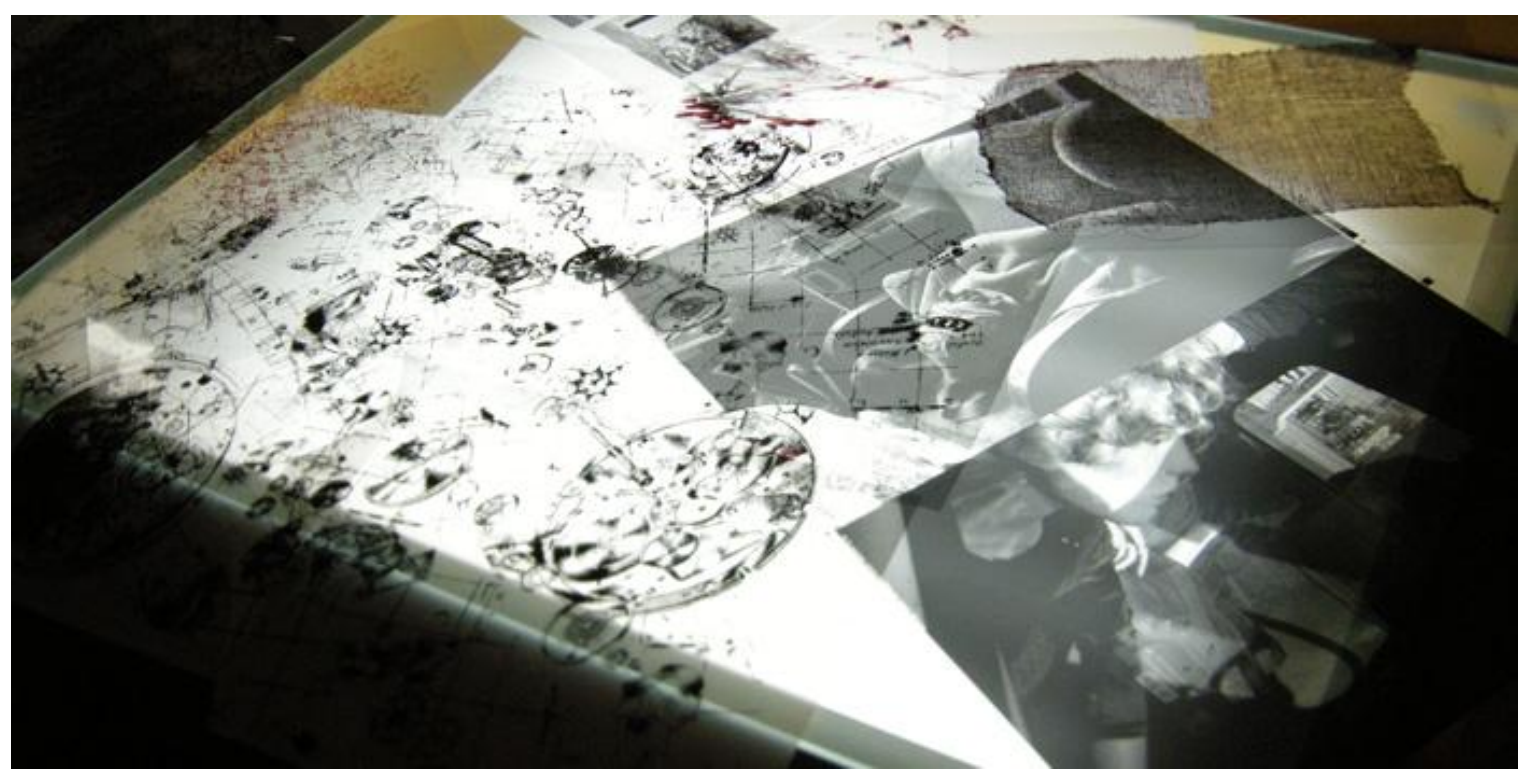

Figura 1: Sobreposição de fotolitos. Fonte: Vostokshop ${ }^{3}$.

Cauduro (2000), afirma que o palimpsesto é originário do papiro. Esta origem, segundo ele, resulta da tentativa de reaproveitamento de antigos pergaminhos considerados de menor importância. Acrescenta, também, que o pergaminho nada mais

\footnotetext{
${ }^{2}$ Disponível em $<$ https://www.ahdictionary.com/word/search.html?q=palimpsest $>$. Acesso em: 15 abri. 2016.

${ }^{3}$ Disponível em: <http://www.vostokshop.eu/el-fotolito-ese-gran-desconocido/>. Acesso em: 14 abri.2016.
} 
erado que um papiro economicamente mais viável, de origem animal, que durava o mesmo tempo, mas se tornava uma matéria-prima mais barata.

É importante lembrar que o palimpsesto não é um movimento artístico temporal ou pontual, ele é uma técnica utilizada desde os primórdios, que tem por resultado uma estética muito própria, conforme é possível verificar na Fig.2.

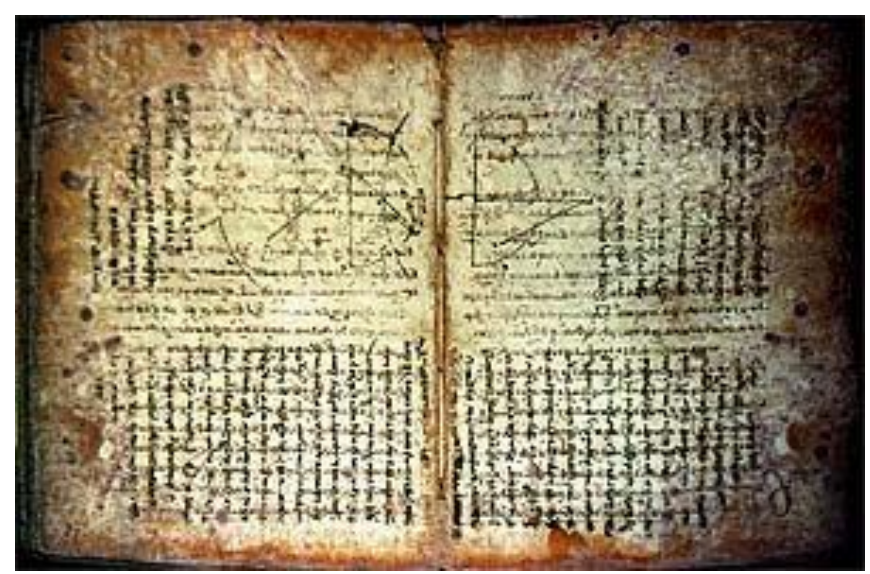

Figura2: Palimpsesto originário de um papiro. Fonte: Desinfeliz ${ }^{4}, 2006$.

Em grego, a origem da palavra palimpsesto significa "raspado novo", portanto, um pergaminho reciclado caracteriza-se como um palimpsesto. Esta afirmação é comprovada pelo fato de que os pergaminhos passavam por um processo de descoloração e raspagem, porém, a nova impressão após esse processo ainda possuía "escritas fantasmas" (que não saiam totalmente do pergaminho anteriormente utilizado). Martins (1996 apud CAUDURO, 2000, p. 135) esclarece também que:

Pensou-se durante muito tempo que esse hábito resultava das intenções piedosas dos monges copistas, que apagavam textos pagãos para inscrever em lugar deles orações e meditações religiosas. Mas, verificou-se posteriormente que não só o palimpsesto existe desde a mais remota antiguidade, como ainda inúmeras orações e trechos religiosos tinham sido raspados em benefício da literatura profana, o texto primitivo, que se destaca com maior ou menor clareza a ação de reagentes químicos.

Acredita-se, então, que quanto mais reciclado for o palimpsesto mais rico ele transformará. Por isso, quanto mais houver interferência maior será o teor estético do mesmo.

É importante também destacar que essa técnica carrega um fardo histórico muito grande e sua importância, em alguns casos, é tanta que ele pode registrar séculos de

${ }^{4}$ Disponível em: <http://desinfeliz.blogspot.com.br/2006/03/o-palimpsesto.html>. Acesso em: 15 abri. 2016. 
história e/ou variados registros. Um palimpsesto que se tornou famoso foi achado em Constantinopla em 1906, que continha sob uma coleção de orações o texto completo em grego de diversos e importantes escritos matemáticos de Arquimedes (CAUDURO, 2000).

Quando se aborda o palimpsesto, abre-se uma grande discussão acerca do assunto, com teorias opostas que se aproximam por vezes, mas poucas informações são legitimadas. Essas discussões entram no âmbito do pós-modernismo e da importância da técnica para o campo das artes, Harvey (1989 apud CAUDURO, 2000, p. 137), por exemplo, afirmou que o palimpsesto tratava-se de um "produto cultural que só cria matérias-primas (fragmentos e elementos), deixando aberto aos consumidores a recomposição desses elementos da maneira que eles quiserem". Portanto, pode-se concluir que para o resultado de um palimpsesto a participação do espectador/consumidor da obra é parte fundamental da sua significação. Isso porque, segundo Cauduro (2000), os palimpsestos se alimentam da anarquia, da fragmentação, da instabilidade, da heterogeneidade, da reciclagem de memórias e de textos descontextualizados, descontínuos, procurando uma maior riqueza na participação do espectador da obra, que produz sentido a essas combinações "irracionais".

O termo palimpsesto também está presente na arquitetura quando é empregado, por exemplo, para referências de escritas em ruínas. Ainda se aplica ao modo típico do tecido urbano contemporâneo que, conforme Harvey (1989), encontramos ao verificar nas cidades formas superpostas umas às outras. Outro exemplo contemporâneo, que também se aplica nas intervenções urbanas, sobretudo na utilização do grafite, que acaba por dar origem a palimpsestos vernaculares muito ricos, é o Muro de Berlim, que pode ser visualizado na imagem que segue: 


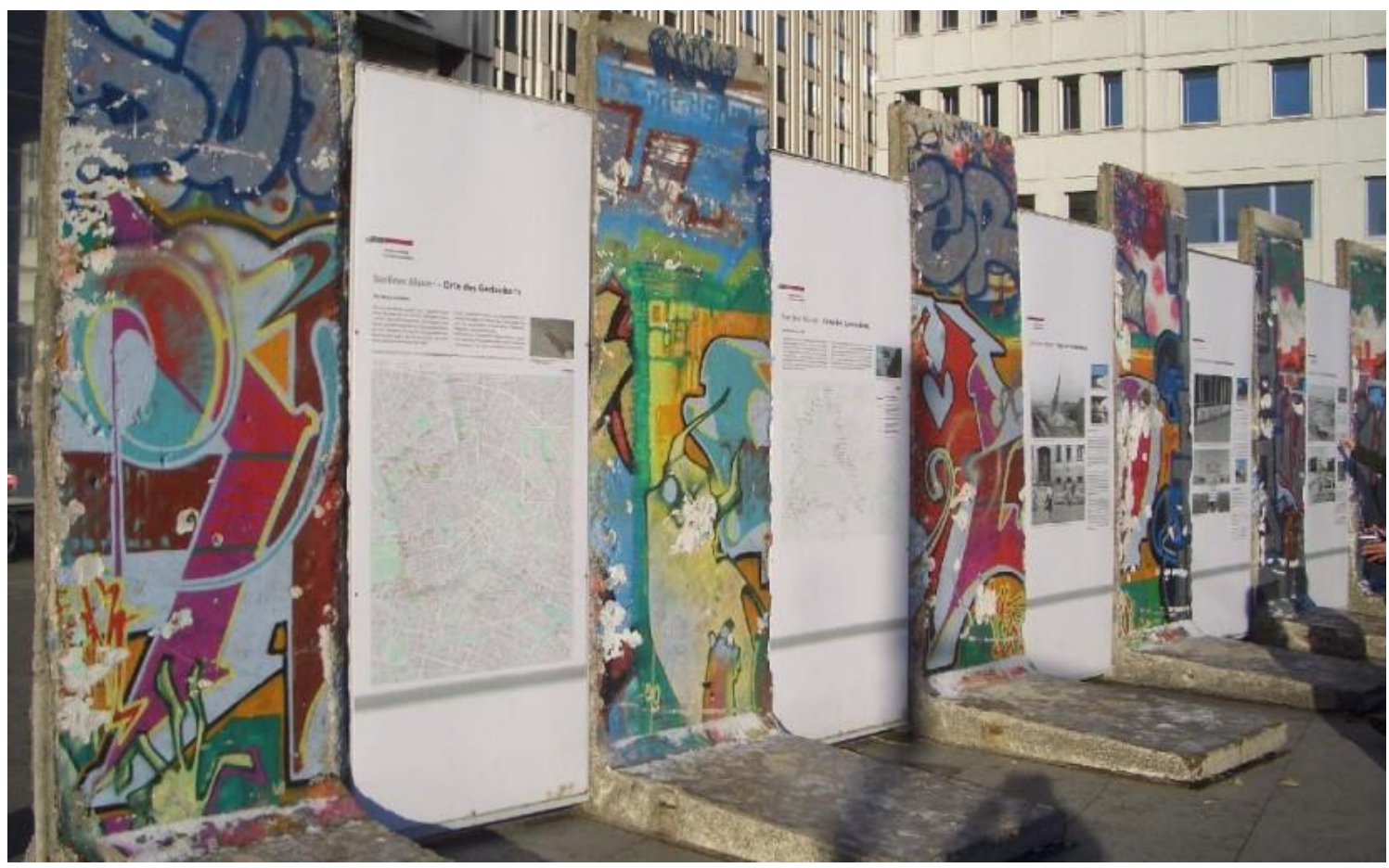

Figura 3: Muro de Berlim e palimpsesto. Fonte: UR Republic ${ }^{5}$.

No Muro de Berlim, as intervenções climáticas e artísticas somam-se de forma desordenada e não planejadas. Porém, as pinturas murais podem ser planejadas, o que é muito comum em cidades como Los Angeles e Londres, que constituem casos típicos do uso de palimpsestos- uma vez que acabam por confundir o espectador em termos de figura e fundo, juntamente com a problematização da diferença entre apresentação e o suporte em suas imagens. Esta técnica é denominada de tromp Poeil (CAUDURO, 2000), e um artista importante que a utiliza chama-se Kent Twichell - que é um produtor de grandes pinturas murais, sobretudo na cidade de Los Angeles, como é possível verificar na Fig. 4:

${ }^{5}$ Disponível em: <http://www.urrepublic.com/25-years-berlin-wall-fell-division-remains/>. Acesso em 15 abri. 2016. 


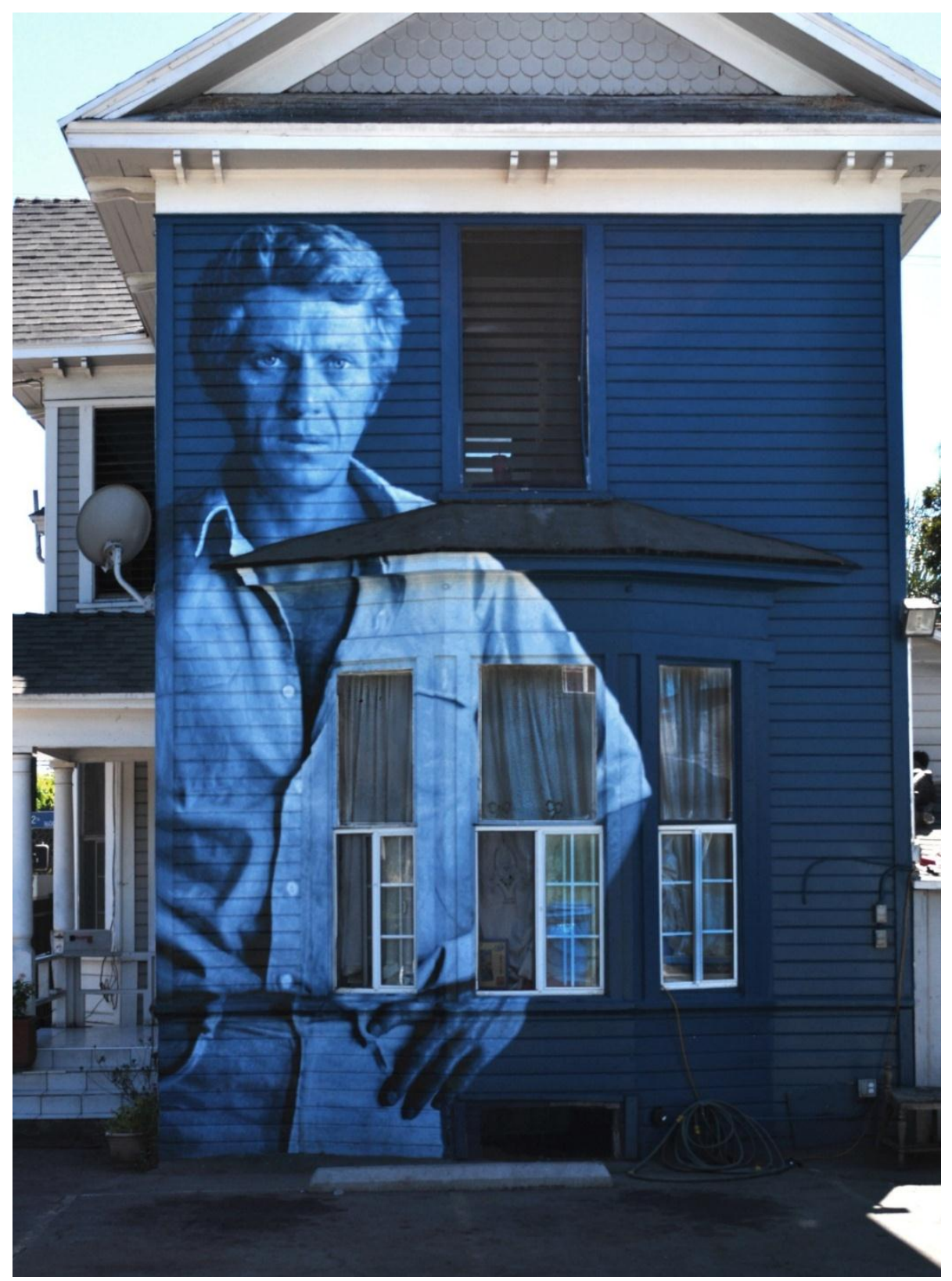

Figura4: Steve McQueen, 1981. Kent Twichell ${ }^{6}$. Fonte: The Other Art Talk ${ }^{7}$

Também se pode observar a técnica do palimpsesto sendo utilizada em trabalhos de colagem. O artista pop italiano Mimmo Rotella, por exemplo, se utiliza da sobreposição de resíduos gráficos, como recortes de cartazes, fotos, jornais, revistas, dentre outros, para criar suas peças.

\footnotetext{
${ }^{6}$ Para acessar a galeria de obras murais do artista vá em: <http://otherarttalk.com/kenttwitchell/>.

${ }^{7}$ Disponível em: <http://otherarttalk.com/kent-twitchell/>. Acesso em: 15 abri. 2016.
} 


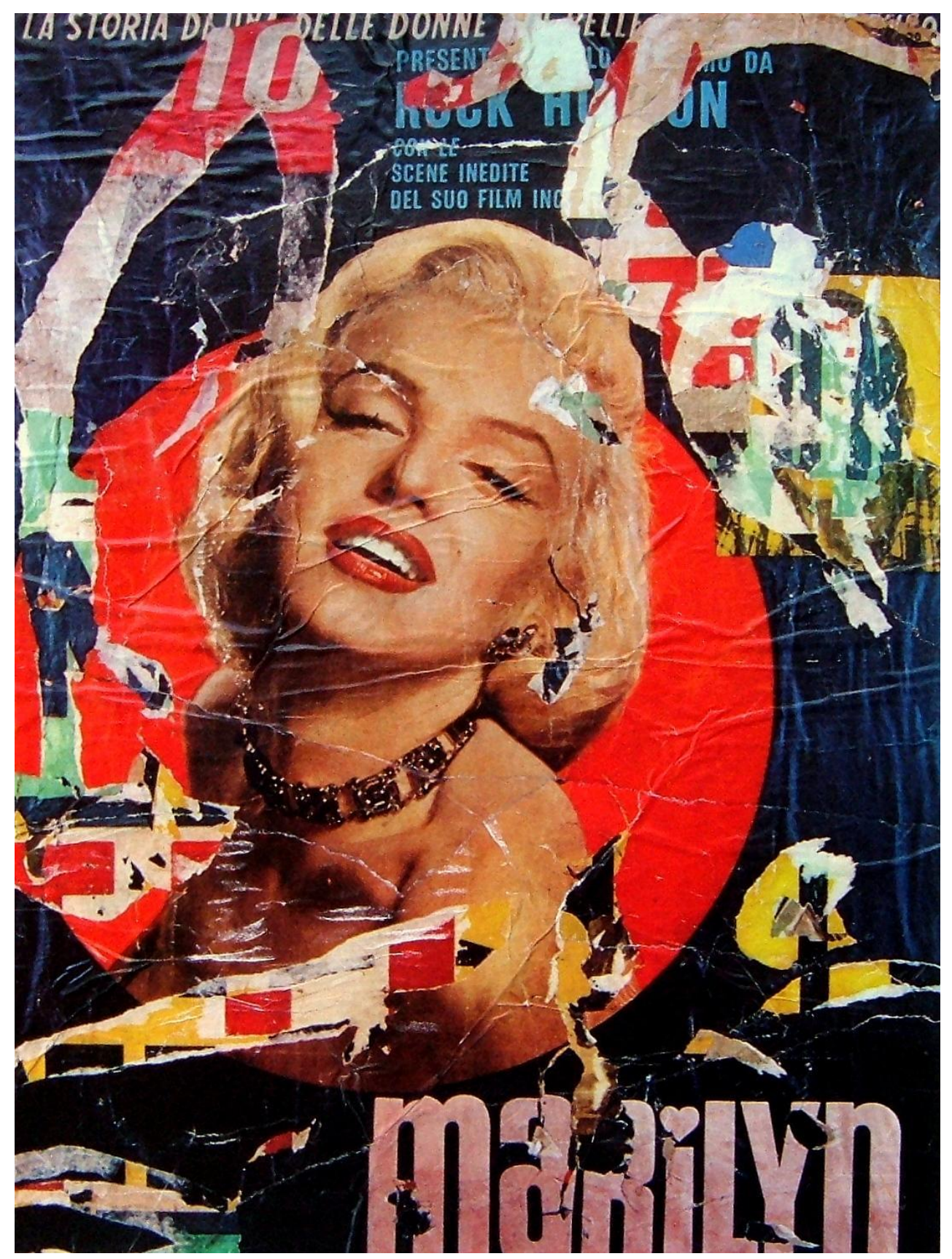

Figura 5: Mirilyn, 1963. Mimmo Rotella. Fonte: L'Arte Spiegata ai Truzzi ${ }^{8}$.

Como é possível observar, suas obras são bastante caracterizadas pela forma de colagem, dotando-se até mesmo de cortes de tecidos. Essa técnica de composição e justaposição de materiais foi muito usada pelos fotógrafos dos anos 1960, juntamente com uma série de designers - que começaram a explorar a utilização de fotomontagens.

${ }^{8}$ Disponível em: <http://lartespiegataaitruzzi.tumblr.com/post/50582728034/mimmo-rotellacatanzaro-1918-milano-2006>. Acesso em: 15 abri. 2016. 
Ainda hoje podemos ver a influência dessa técnica em obras de moda, artes plásticas e design como é possível analisar na Fig.6.

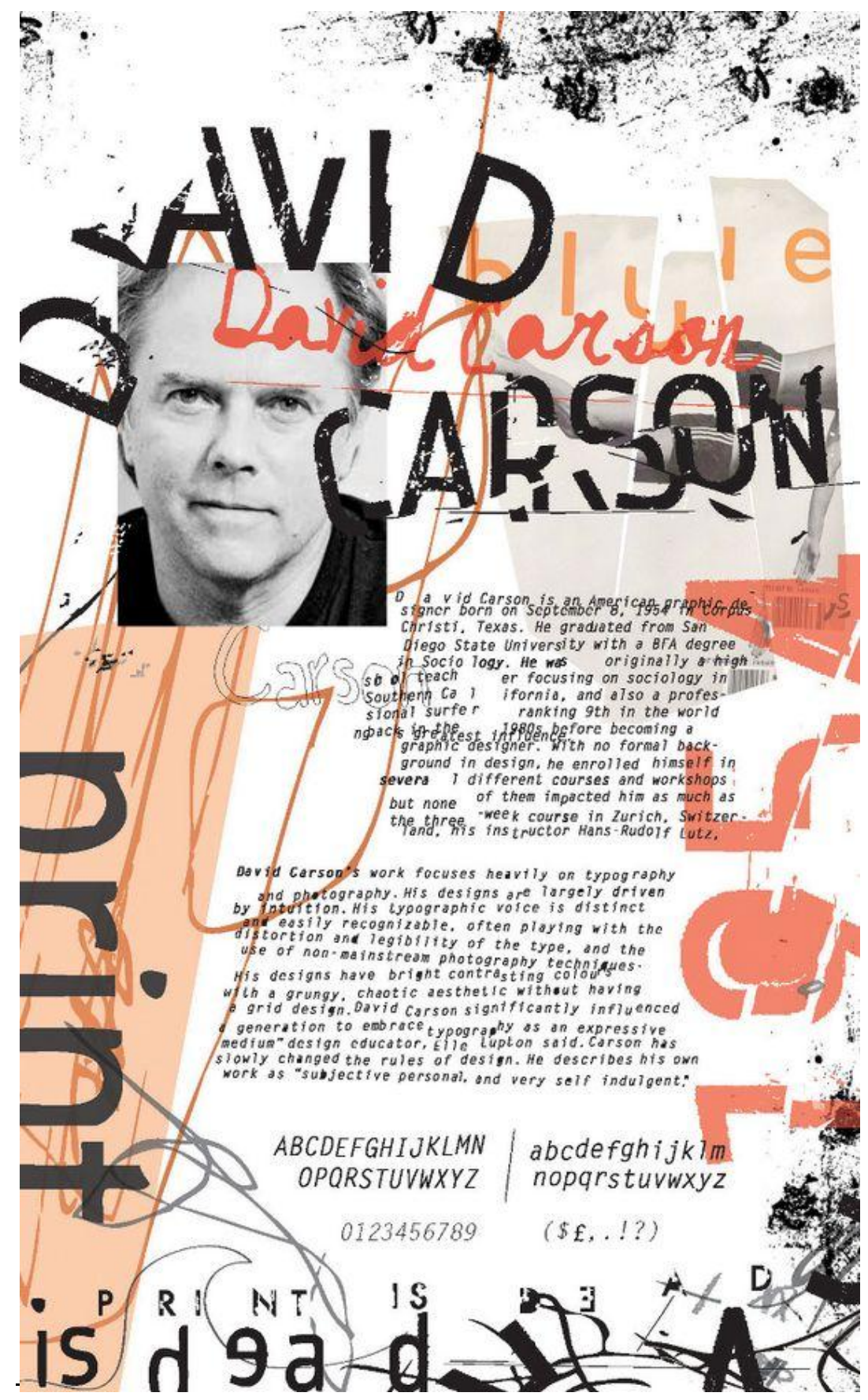

Figura 6: David Carson, s/ data. Fonte: Maru Ocantos ${ }^{9}$.

Na pintura também é possível identificar a velatura ou o chamado "efeito palimpsesto" (CAUDURO, 2000), produzido de maneira intencional. Essa técnica

${ }^{9}$ Disponível em <https://br.pinterest.com/pin/393924298637804910/>. Acesso em: 15 abri. 2016. 
ocorre basicamente pela sobreposição de camadas de tinta, onde manchas de tintas dispostas ao interesse do artista são cobertas com uma mão de tinta de outra cor, levemente aplicada para transparecer as camadas anteriores. A Fig. 7 apresenta a representação de uma velatura artística.

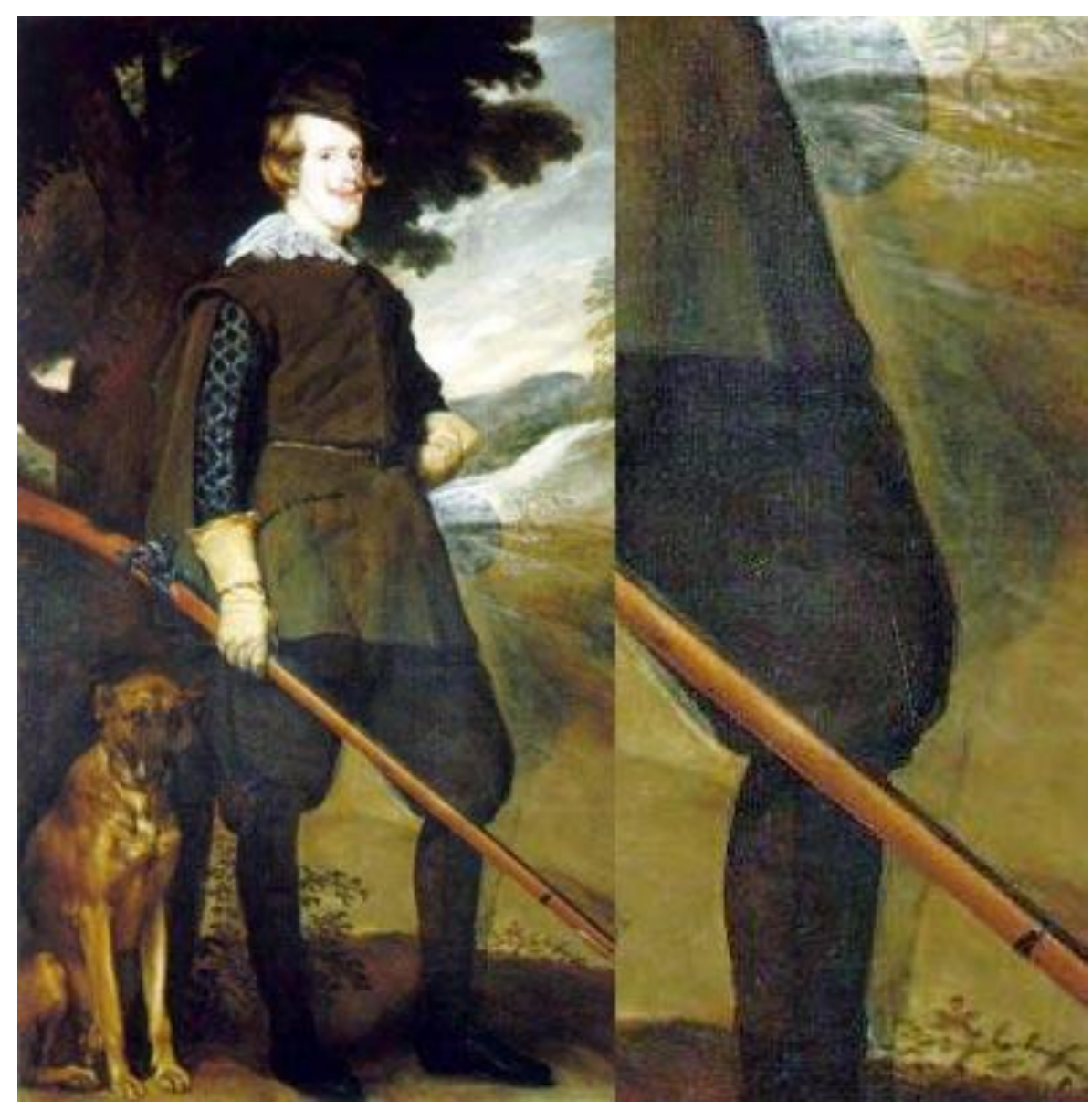

Figura 7: Exemplo velatura ${ }^{10}$ pintura de Velasquéz. Fonte: Cozinha da pintura ${ }^{11}$.

Diante do que foi estudado, é importante destacar que o palimpsesto é atemporal e está presente em vários movimentos estético-artísticos. Por esse motivo, a técnica do palimpsesto é transmutada pelo modernismo, pós-modernismo e também na contemporaneidade. No modernismo estava presente, por exemplo, nas obras da vanguarda do estilo cubismo, momento em que artistas, como George Braque, utilizam

\footnotetext{
${ }^{10}$ Percebe-se que, no campo das Artes, o palimpsesto também denuncia marcos do processo. Este fato se dá por camadas sobrepostas que podem apontar modificações na obra, o que talvez, em alguns casos, não seja interessante para o artista. Na fig. 7, percebe-se o marco da perna da figura representada em uma possível sombra no resultado final da obra.

${ }^{11}$ Disponível em: <http://www.cozinhadapintura.com/2011/11/diferencas-dos-metodos-diretoe.html>. Acesso em: 15 abri. 2016.
} 
da sobreposição de colagens para dar sentidos e trazer formas para o espectador- além de tornar a tela que era bidimensional em um objeto tridimensional.

Já no pós-modernismo acabou por criar formas orgânicas, tais como no psicodelismo, período em que alguns artistas se utilizaram de colagens de variadas fontes e cores para a composição de telas, além da criação de outras peças tais como cartazes. Para isso, se toma como exemplo o trabalho de Robert Rauschenberg, o pop artista foi um dos promissores expoentes do pós-modernismo. Ele utiliza a técnica do palimpsesto que é destacado, principalmente, em suas obras de serigrafia fotográfica e óleo sobre tela, como no caso da Fig. 8:

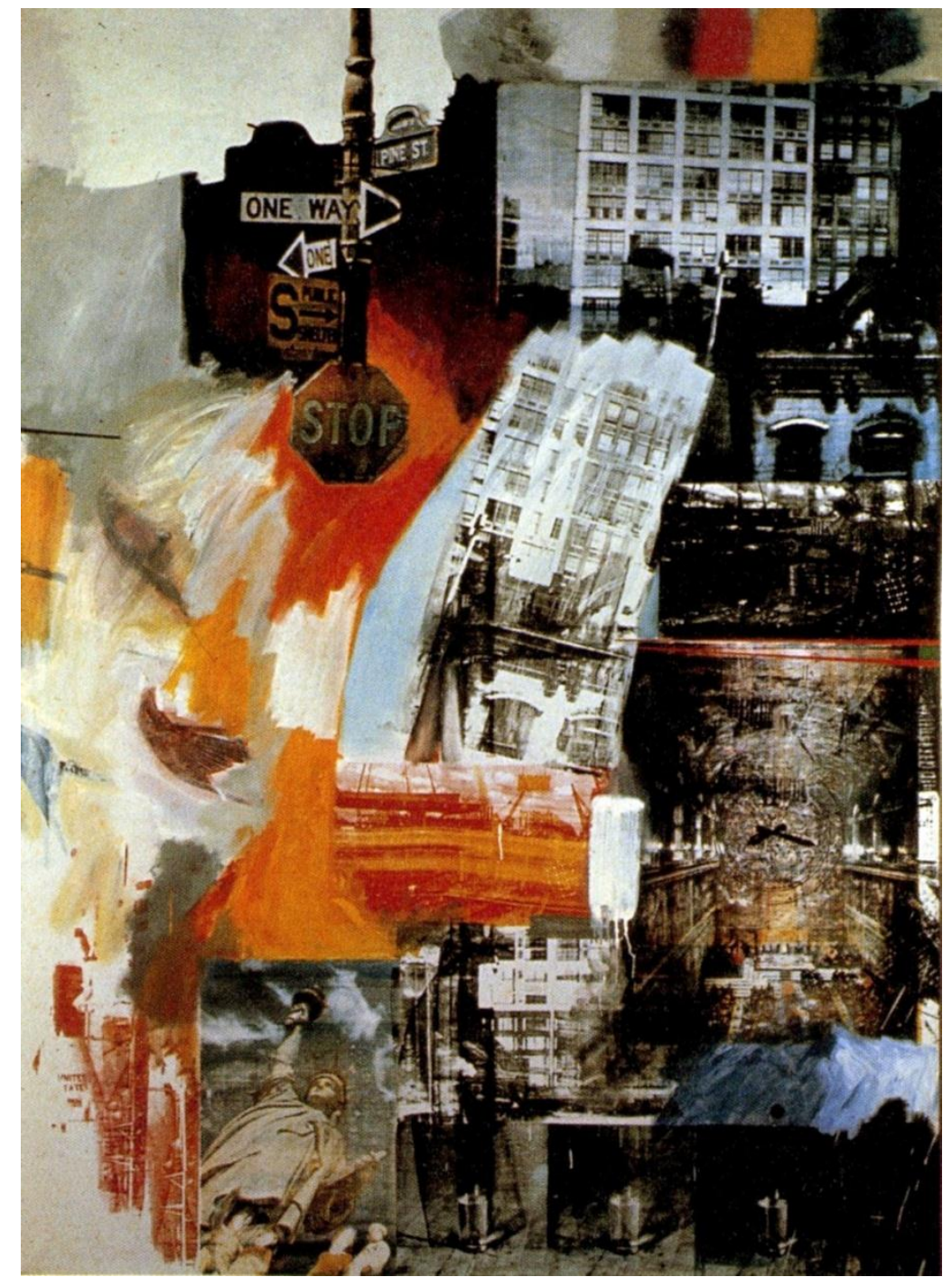

Figura 8: Estate, 1963. Robert Rauschenberg. Fonte: Archive of Affinities ${ }^{12}$.

\footnotetext{
${ }^{12}$ Disponível em: <http://archiveofaffinities.tumblr.com/post/16963536433/robert-rauschenbergestate-1963>. Acessado em: 15 abri. 2016.
} 
E, por fim, na contemporaneidade, o palimpsesto tem sido utilizado em exposições, como instalações; e também em peças isoladas (tais como na publicidade), por vezes ocorrendo na utilização de transparência de camadas de tecidos, de papeis, dentre outros materiais. É bastante frequente em cartazes, que apresentam colagens manuais, ou são formados por camadas realizadas com o auxílio de programas de computadores - como aconteceu na Avenida Paulista, no mês de abril de 2014, em meio aos protestos que estão assolando o Brasil que enfrenta uma séria crise política(ver Fig. 9).

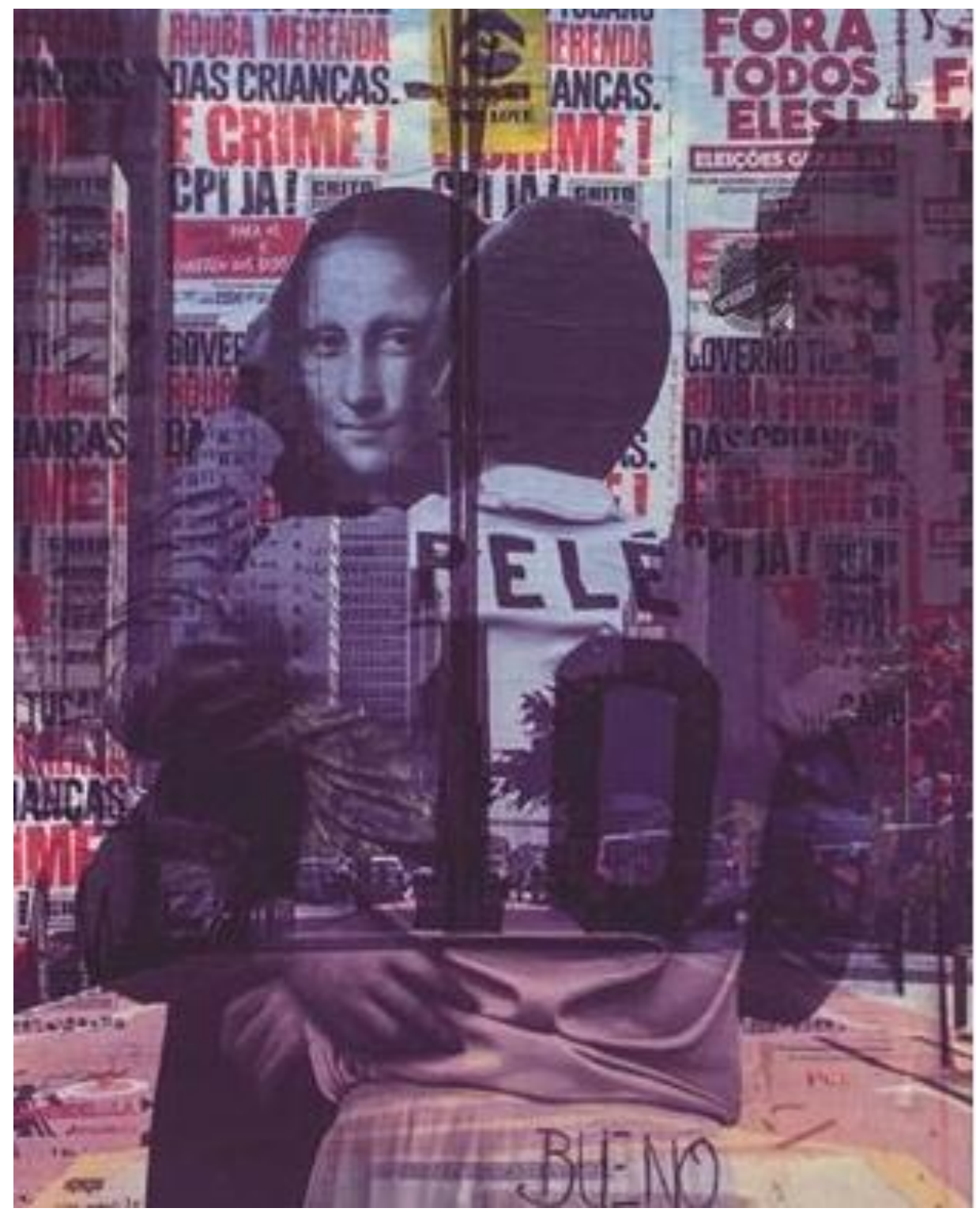

Figura 9: Painel Avenida Paulista. Fonte: Artur Silva ${ }^{13}$.

\footnotetext{
${ }^{13}$ Disponível em <https://www.facebook.com/arturcunhas?fref=ts>. Acesso em: 15 abri. 2016.
} 
O que se observou é que o palimpsesto como técnica utilizada por artistas e designers pós-modernos foi uma experiência de sequências continuamente cambiantes, justapostas e de posições em camadas, como parte de uma estrutura descentrada - sem lógica - de associações, como defendia Margot Lovejoy (1997).

$\mathrm{Na}$ área do design gráfico, precisamente citando os pioneiros, destacam-se pelo uso os seguintes nomes: Wolfgang Weingart, April Greiman, Neville Brody, Studio Dumbar e David Carson. O palimpsesto é tão utilizado que hoje continua a se encontrar essa estética em sites de designers, de artistas, de empresas de comunicação, dentre tantas peças espalhadas pelo mundo.

A estética do palimpsesto, para Cauduro (2000), pode ser alongada em outras práticas visuais, tais como na fotografia, nos HQs, nos videoclipes e filmes, para confirmar que essa é uma estética típica e onipresente da visualidade pós-moderna. Ressalta ainda que:

\footnotetext{
o importante é termos podido identificar essa nova estética, que está enriquecendo nossa percepção visual e, tomara, valorizando cada vez mais nosso imaginário, por estimular significativamente nossa participação na construção da realidade (Ibidem, p 138).
}

Com base no mapeamento sobre as possibilidades da utilização do palimpsesto o que se percebe é que mesmo que o designer queira privilegiar um sentido objetivo em uma determinada peça, a estética associada à configuração de tal produto gráfico não permitirá essa objetivação nas obras, pois ela será interpretada pelo espectador, ainda que o produtor procure conduzir essa interpretação- e talvez resida aí a profundidade de tal estética.

Por isso, ouso do palimpsesto abriu um leque de possibilidades, muito em função dessas infinitas interpretações das peças, tanto para o espectador quanto para o artista/designer da obra. Isso ocorre, pois o resultado estético do palimpsesto trabalha com a mistura de mensagens, sentidos e significados para a arte e mesmo para o design.

\section{CONCLUSÕES}

A partir da revisão de literatura apresentada neste artigo, pode-se concluir que o palimpsesto é um recurso riquíssimo para a área do design - que no seu uso trabalha com o imaginário do espectador sendo capaz de instigar novos significados, criando peças de comunicação muito potentes. Sendo assim, visualiza-se essa técnica como um 
possível fator diferencial para os designers, ou seja, se eles compreenderem os possíveis usos do palimpsesto no trabalho de design poderá atingir resultados surpreendes, trazendo novas leituras a partir de uma estética histórica, mesmo que seja tão pouco pesquisada, diferentemente de outros movimentos e estéticas visuais. Isso ficou muito explícito ao realizar esta abordagem teórica para a organização deste artigo - momento em que se observou a pouca quantidade de fontes existentes sobre o palimpsesto. Por isso, entende-se a importância da teorização do palimpsesto como estética, possibilitando aos designers, e demais profissionais, uma potente forma de expressão visual. A partir desta fase concluída, qual seja: de captação de referências e de teorias, pretende-se agora elaborar peças que se utilizem da estética do palimpsesto - com o intuito de explorar essa estética - que pode ser estrategicamente utilizada na contemporaneidade, nas mais diversas aplicações, como foi possível perceber ao longo deste estudo.

\section{REFERÊNCIAS}

CAUDURO, Flávio. Design Gráfico \& pós-modernidade. Rio Grande do Sul: Revista FAMECOS, 2000.

HOLLIS, Richard. Design Gráfico: Uma história concisa. São Paulo: Editora Martins Fontes, 2001.

MEGGS, Philip B.; PURVIS, Alstom W. História do Design Gráfico. São Paulo: Editora Cosacnaify, 2004. Ed. 4.

KNAPP, Marina. Intervenções artísticas no espaço da cidade: Provocações e possibilidades educativas. Rio Grande do Sul, 2011.

SCHOFIELF, Matthew. 25 years after Berlin Wall Fell, division remains. Washigton, 2014. Disponível em <http://www.urrepublic.com/25-years-berlin-wall-fell-divisionremains/>. Acesso em: 15 abri. 2016.

Kent Twitchell. 2014. Disponível em

<http://otherarttalk.com/kent-twitchell/>. Acesso em: 15 abri. 2016.

L'Art Speigata ai Truzzi: nella loro lingua. Disponível em <http://lartespiegataaitruzzi.tumblr.com/post/50582728034/mimmo-rotella-catanzaro1918-milano-2006>. Acesso em 15 abril. 2016. 
Palimpsesto. 2008. Disponível em

$<$ http://maisumpalimpsesto.blogspot.com.br/search?q=muro+de+berlim>. Acesso em 15 abril. 2016.

Diferenças entre os métodos diretos e indiretos. 2011.

Disponível em <http://www.cozinhadapintura.com/2011/11/diferencas-dos-metodosdireto-e.html>. Acesso em: 15 abri. 2016. 